\title{
Impact of Number of Phases on Electromagnetic Torque Characteristics of Transverse Flux Permanent Magnet Machines
}

\author{
Ali Alaeddini ${ }^{1 *}$, Hamed Tahanian ${ }^{1}$, Ahmad Darabi $^{1}$ \\ ${ }^{1}$ Faculty of Electrical and Robotics Engineering, Shahrood University of Technology, Shahrood, Iran \\ *corresponding author, E-mail: alaeddini.ali@gmail.com
}

\begin{abstract}
This paper presents an investigation on the influences of number of phases of Transverse Flux Permanent Magnet (TFPM) machines on the characteristics of developed electromagnetic torque. Electromagnetic torque is expressed in terms of the Fourier series of phase currents and internal voltages. After some algebraic and trigonometric calculations, a general equation is obtained that establishes a relationship between the electromagnetic torque ripples, number of phases and harmonic contents of both internal voltages and phase currents. This result is significant when it is required to design a few specific number of identical single-phase TFPM machines which finally they will be assembled such that to build a multi-phase machine with a minimum torque ripple. The design parameters of a case study Claw Pole TFPM machine are introduced with some details and a few FE based simulation results are given as the validations of the analytical approach of the present paper. The simulation results show clearly the impact of each harmonic of the internal voltages and phase currents on the torque ripple for various numbers of phases leading the designer to find out which number of single-phase machine combinations is the optimum one regarding the torque ripple.
\end{abstract}

\section{Introduction}

Transverse Flux Permanent Magnet (TFPM) machines, introduced in the 1980s [1], have gained increasing attention because of their flexible topologies, high torque density and high efficiency $[2,3]$. Unlike conventional machines, electromagnetic torque in transverse flux machines is proportional to the number of poles [4-6]. Because of this unique feature, the torque density of these machines could increase up to several times of conventional machines by increasing the number of poles. As the mass and volume of electric machines are dependent on their nominal torque, this unique feature of TFPM machines is used in industrial arms and 3-D printers [7], electric vehicles [8, 9], and low speed applications, such as railway traction $[10,11]$, wind power generators [12-14], wave energy generators [15], ship propulsion motors [16] and marine propulsion motors [17], where access to high torque density is critical [18-20].

Topological classification of TFPMs are divided into double-sided and single-sided topologies which the former, despite of its complicated structure, benefits from producing higher amount of power. On the other hand, the latter offers simple structure but produces lower amount of power in comparison with the double-sided. Therefore, the both could not cover simple structure and higher power production [2123]. However, among different TFPM topologies, the Claw Pole structure shows interesting features, mentioned previously.

In many circumstances, swimming of electromagnetic torques is a big problem concerning the performances of electric machines and loads. Additionally, ripples of electromagnetic torque are mostly the main sources of noise and vibration of electrical machines [24]. In many studies, it is shown that increasing of average torque of permanent magnet machines leads to torque ripple rise. Thus, the torque ripple decline with no effect on the amount of average torque is a problematic issue in designing stage [25]. There have been extensive efforts to reduce the ripples of electromagnetic torque to improve the quality of electrical machines performance.

It is well known that existing low frequency harmonics in the phase currents and internal voltages of synchronous machines generate oscillating or ripples involved electromagnetic torque. Hence, it is desirable to design the machine in a way that lowers harmonic contents of currents and internal voltages as much as possible. Many studies have discussed various methods of ripple reduction in permanent magnet synchronous machines. In some research work, rotor and/or permanent magnet shape are designed so as to achieve a more sinusoidal back EMF waveform aiming at torque ripple reduction. Different axially arrangement of permanent magnets on rotor are investigated [26]. It is show that this method can effectively reduce torque ripple factor by $16.5 \%$, but resulting in a significant drop in torque density. In [27], both rotor and flux concentrate shapes are designed in order to obtain a drop in harmonics of magnetic field from $32.5 \%$ to $5.5 \%$, however, average torque is reduced by $18.4 \%$. Similarly, the total harmonic distortion (THD) of back EMF is reduced by $5.25 \%$, while the average torque is declined by $6 \%$, with the usage of asymmetric rotor shape design [28]. Method of inverse cosine rotor shaping with radial direction is utilized for declining of THD of the back EMF waveform [29]. In [30], several rotor segment are axially optimized to reduce torque ripple by $50 \%$, but resulting in $9 \%$ decline of average torque. Permanent magnet shape design is optimized in order to make the back EMF more sinusoidal, THD reduces from $14.6 \%$ to $1.7 \%$, whereas the average torque decreases by $6.2 \%$ [31]. The method of rotor shaping causes 
equivalent airgap to increase in interior permanent magnet (IPM) machines and permanent magnet magneto motive force (MMF) to decrease in surface-mounted permanent magnet (SPM) machines. This effect leads to the average toque reduction [32]. Another method of ripple torque reduction is magnet shifting. In [33], three different method consisting one pole, one pole-pairs and two pole-pairs as repeating unit are used which result in torque ripple $20.2 \%$, $23.2 \%$, and $23.7 \%$, respectively. Nevertheless, these methods cause the average torque to reduce by $4.8 \%, 2.7 \%$, and $3.2 \%$, respectively. In the other study, degree mechanical offset between two adjacent claw poles of stator claw pole permanent magnet machines is set to torque ripple decline $[34,35]$. For instance, in [35], the mechanical offset is set to 9 degree so as to achieve reduction of THD of back EMF from $9.5 \%$ to $7.5 \%$, however, the fundamental peak of back EMF of 9 degree offset with respect to no mechanical offset decreases from $25.6 \mathrm{~V}$ to $24.8 \mathrm{~V}$. The main drawback of these techniques is a substantial decline in average torque.

Due to usage of TFPM machines in low speed and high torque applications, more attention should be paid to the electromagnetic torque of the machine in the process of design and optimization. There are several parameters and structural factors affecting both the average value and the ripples of electromagnetic torque of TFPM machines. Among the parameters, the number of phases is a factor that has a great influence on the torque ripples of this type machines. In some research work, multiphase TFPM machines have been investigated for different purposes such as better understanding of mechanical characteristics of a 5phase one [36], 6-phase one for low speed reciprocating power generation [37], design of topology and drive system for a 4-phase one $[38,39]$ and effects of teeth geometry on torque ripple for 2-phase one [40]. A few number of research has focused on effect of the number of phases on torque ripples. For instance, in [41], cogging torque are investigated for a single phase, 2-phase and 4-phase TFPM machine. Similarly, the influence of number of phases including of single phase, 2-phase and 4-phase are examined on electromagnetic torque ripples [42]. Therefore, it is necessary to pay more attention on investigation the effect of the number of phases on electromagnetic torque ripples.

For the most of the multi-phase TFPM machines, each phase is designed and built individually as a single-phase machine and then a few single-phase machines are assembled on a common shaft to present a multi-phase machine. Therefore, due to the lack of electromagnetic coupling between the phases, the waveform of each phase internal voltage is independent on the number of phases. However, the number of phases will determine percentage participations of each harmonic of the internal voltages and phase currents in generation of the torque ripples of the final multi-phase machine. Therefore, optimal number of phases in the process of design could be selected in a way that prevents major harmonics of internal voltages and phase currents to take part in the torque ripples.

The paper is organized as follow. In Section 2, the structure and design process of Claw Pole TFPM is presented. General equations which relates waveform of the electromagnetic torque to waveforms of the phase current and internal voltage for different number of phases are derived in Section 3. Section 4 is devoted to a discussion on harmonic pairs of the internal voltage and phase current which take part in the electromagnetic torque ripples for the $m$-phase synchronous machines and harmonic pairs which produce harmonic components of electromagnetic torque with nonzero average value. In Section 5, the optimal phase number of Claw Pole TFPM machine as a case study is determined. Finally, Conclusions are summarized in Section 6.

\section{Structure and design of claw pole TFPM machine}

\subsection{Structure of claw pole TFPM machine}

Claw Pole armatures made of soft magnetic composites (SMC) materials was designed in order to improve magnet utilization in TFPM machines [43]. Fig. 1 shows one pole pair of one phase of a Claw Pole TFPM machine. According to Fig. 1, permanent magnets (PMs) are situated adjacent of flux concentrators in rotor and the stator consists of a back core and claw teeth which enclose the armature winding. One phase is constructed by putting together these pole pairs around the axis of motor as illustrated by Fig. 2 .

Multiphase structure is achieved by stacking shifted phases along the machine axis direction. In order to reach smooth torque, the phases have to be shifted by $360 / m$ electrical angle, where $m$ is the number of phases. This phase shift can either be applied to stator teeth or rotor elements. For instance, a six-phase claw pole TFPM motor is illustrated in Fig. 3.

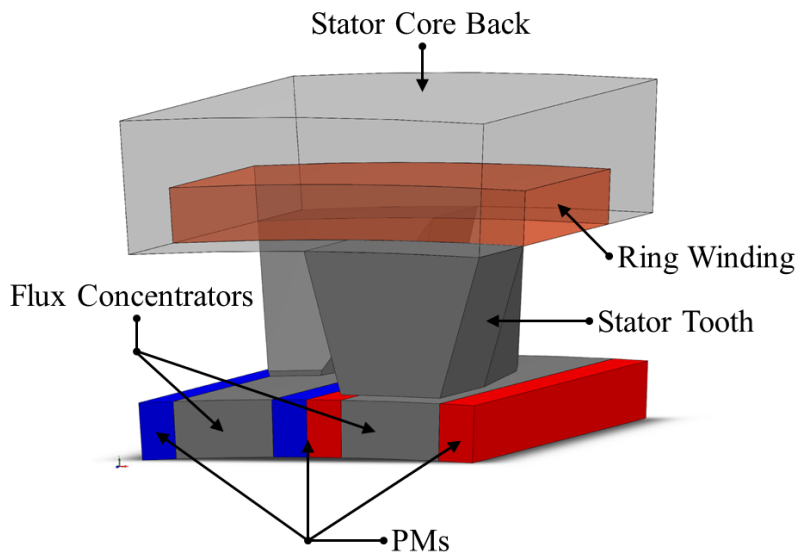

Figure 1: One pole pair of one phase of a claw pole TFPM motor.

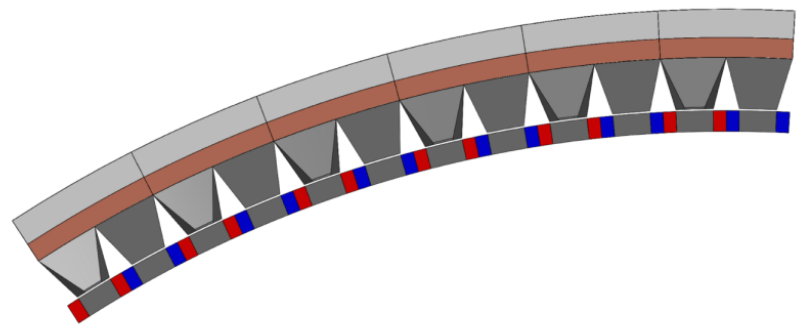

Figure 2: One phase of a claw pole TFPM motor partially. 


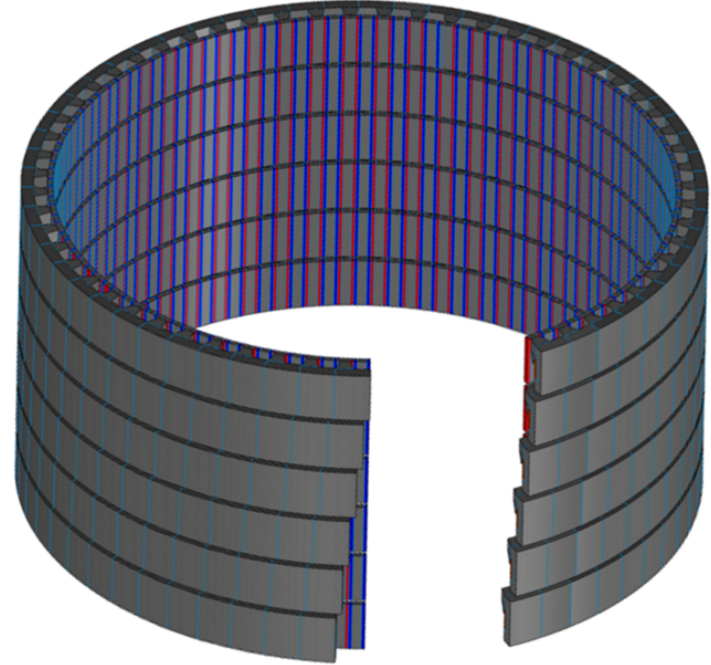

Figure 3: Six-phase claw pole TFPM motor

\subsection{Designing a claw pole TFPM machine}

It is desired to use accurate equations for calculation of some dimensions of Claw Pole TFPMs. For this paper, design of Claw Pole TFPM is based on the main sizing equations which are introduced in below.

Length of the stator tooth $d_{o s}$ is calculated by:

$$
d_{o s}=\left(D_{g} / 2\right)\left[\frac{2 K_{c o}\left(1-K_{l t}\right)}{\left(1-K_{s}\right)\left(1+K_{m}\right)}-1\right] \text {, }
$$

where $D_{g}$ is the air gap surface diameter, $K_{s}$ is the ratio of the slot axial length $L_{s s}$ over the axial length of each phase $L_{s}, K_{m}$ is the ratio of magnet arc to the flux concentrator arc in each pole of the rotor, and $K_{c o}$ is the ratio of area of the rotor pole covered by the stator pole to the area of the rotor flux concentrator. $K_{l t}$ is a factor related to the flux leakage in the stator teeth. In design process, some coefficients of sizing equations, i.e. $K_{l t}$ and $K_{l p m}$ are difficult or impossible to be calculated analytically because claw pole TFPM machines have complex structure and the nature of flux paths are threedimensional. Consequently, the accurate alternative for estimation of these coefficients is FEA in which the initial guess is used for the first design in FE modeling. Then, these coefficients are extracted, being utilized in the next step in order to calculate the coefficient within acceptable error range. For instant, $K_{l t}$ is obtained through the division of flux entered to stator yoke by the flux entered to stator tooth.

To reduce the leakage flux taken placed between the adjacent stator teeth, a minimum value is assigned for $d_{o s}$ which is given by:

$$
d_{o s, \min }=\frac{L_{s}}{2}\left(2 K_{c o}+K_{s}-1\right)
$$

Therefore, if value of $d_{o s}$ obtained from (1) becomes lower than $d_{o s, \min }$, length of the stator tooth is assumed to be $d_{o s, \min }$.

Thickness of the stator back iron $d_{c s}$ is evaluated by:

$$
d_{c s}=\frac{\left(1-K_{s}\right)\left[\left(D_{g} / 2\right)+d_{o s}\right] L_{s}}{4\left[\left(D_{g} / 2\right)+d_{o s}+d_{w s}\right]},
$$

where, $d_{w s}$ is radial length of the stator slot. The other key dimension is radial length of the permanent magnets $H_{p m}$ which is calculated by:

$$
H_{p m}=\frac{\pi B_{g} D_{g}}{4 p\left(1-K_{l p m}\right) B_{m}},
$$

where $B_{g}$ is average flux density in the air gap, $p$ is the number of pole pairs, $B_{m}$ is flux density of the permanent magnet at the operating point, and $K_{l p m}$ is a factor related to flux leakage of the permanent magnets (flux of PMs which doesn't enter the stator teeth). $K_{l p m}$ is determined like $K_{l t}$.

\section{Electromagnetic torque}

Waveforms of the internal voltage, hence its harmonic content, depends on the structure and constructive materials of the machine and the level of core saturation. Harmonics of the terminal voltage and internal voltage and also the rotor magnetic saliency introduce harmonic content of the phase currents. Due to inductive nature of the armature circuits, harmonics of phase currents which are caused by the terminal and internal voltages are filtered greatly. Therefore, THD of the phase currents is usually much lower than the internal voltage THD. However, the TFPM machines are mostly supplied by available low voltage sources. In these circumstances when a high power machine is supplied by a low voltage, the amplitudes of the phase current and internal voltage harmonics would be comparable. Therefore, to derive a general relationship between the number of phases and electromagnetic torque ripples, both harmonics of internal voltage and phase current should be considered.

Therefore, in this section, the electromagnetic torque is expressed in terms of the internal voltage and phase current waveforms by using Fourier series. These calculations are valid for all types of synchronous machines, such as ordinary rotor wounded machines, permanent magnet synchronous machines, and brushless DC machines. For some reasons, first of all the waveform of electromagnetic torque for an $m$ phase machine $(m \geq 3)$ is derived. 2-phase and single phase machines are considered separately.

\section{1. $m$-Phase machines $(m \geq 3)$}

For an $m$-phase machine, the internal voltage $e_{n}$ of phase $n$ is written as:

$$
\begin{gathered}
e_{n}\left(\omega_{e} t\right)=\sum_{h=1}^{\infty} E_{h} \cos \left[h \omega_{e} t-h(n-1) \frac{2 \pi}{m}+\theta_{e h}\right] \\
n=1,2,3, \ldots, m .
\end{gathered}
$$

In which $\omega_{e}, h, E_{h}$, and $\theta_{e h}$ are the fundamental electric angular frequency, the harmonic order, the amplitude of $h^{\text {th }}$ harmonic of the internal voltage, and the $h^{\text {th }}$ harmonic phase angle, respectively. Similarly, current of phase $n$ could be written as:

$$
\begin{gathered}
i_{n}\left(\omega_{e} t\right)=\sum_{k=1}^{\infty} I_{k} \cos \left[k \omega_{e} t-k(n-1) \frac{2 \pi}{m}+\theta_{i k}\right] \\
n=1,2,3, \ldots, m,
\end{gathered}
$$

where $k, I_{k}$, and $\theta_{i k}$ are the harmonic order of phase current, the amplitude of $k^{\text {th }}$ harmonic of phase current, and the $k^{\text {th }}$ harmonic phase angle, respectively.

Instantaneous electromagnetic torque $T_{e}$ is defined as:

$T_{e}\left(\omega_{e} t\right)=\frac{\sum_{n=1}^{m} e_{n} i_{n}}{\omega_{r}}$, 
where $\omega_{r}$ is the angular speed of rotor. In steady state, $\omega_{r}$ is constant. For synchronous machines $\omega_{r}$ is equal to $\omega_{e}$ in steady state. Substitution of (5) and (6) into (7) results in:

$$
\begin{aligned}
T_{e}\left(\omega_{e} t\right)= & \frac{1}{\omega_{r}} \sum_{n=1}^{m}\left\{\sum_{h=1}^{\infty} E_{h} \cos \left[h \omega_{\mathrm{e}} t-h(n-1) \frac{2 \pi}{m}+\theta_{h}\right]\right. \\
& \left.\times \sum_{k=1}^{\infty} I_{k} \cos \left[k \omega_{e} t-k(n-1) \frac{2 \pi}{m}+\theta_{i k}\right]\right\},
\end{aligned}
$$

$h^{\text {th }}$ harmonic of internal voltage and $k^{\text {th }}$ harmonic of phase current produce a component of electromagnetic torque $T_{e}^{h, k}$ which is given by:

$$
\begin{aligned}
T_{e}^{h, k}\left(\omega_{e} t\right)= & \frac{E_{h} I_{k}}{\omega_{r}} \sum_{n=1}^{m}\left\{\cos \left[h \omega_{\mathrm{e}} t-h(n-1) \frac{2 \pi}{m}+\theta_{e h}\right]\right. \\
& \left.\times \cos \left[k \omega_{\mathrm{e}} t-k(n-1) \frac{2 \pi}{m}+\theta_{i k}\right]\right\} .
\end{aligned}
$$

Using product to sum identities, (9) is transformed to

$$
\begin{aligned}
& T_{e}^{h, k}\left(\omega_{e} t\right)=\frac{E_{h} I_{k}}{2 \omega_{r}} \\
& \times \sum_{n=1}^{m}\left\{\cos \left[(h-k) \omega_{\mathrm{e}} t-(h-k)(n-1) \frac{2 \pi}{m}+\left(\theta_{e h}-\theta_{i k}\right)\right]\right. \\
& \left.\quad+\cos \left[(h+k) \omega_{\mathrm{e}} t-(h+k)(n-1) \frac{2 \pi}{m}+\left(\theta_{e h}+\theta_{i k}\right)\right]\right\} .
\end{aligned}
$$

Equation (10) shows that for each pair of harmonics of internal voltage and phase current, the produced electromagnetic torque could be divided into two parts as:

$$
T_{e}^{h, k}\left(\omega_{e} t\right)=T_{1}^{h, k}\left(\omega_{e} t\right)+T_{2}^{h, k}\left(\omega_{e} t\right),
$$

where $T_{1}^{h, k}$ and $T_{2}^{h, k}$ are given by:

$$
\begin{aligned}
& T_{1}^{h, k}\left(\omega_{e} t\right)=\frac{E_{h} I_{k}}{2 \omega_{r}} \\
& \times \sum_{n=1}^{m} \cos \left[(h-k) \omega_{\mathrm{e}} t-(h-k)(n-1) \frac{2 \pi}{m}+\left(\theta_{e h}-\theta_{i k}\right)\right], \\
& T_{2}^{h, k}\left(\omega_{e} t\right)=\frac{E_{h} I_{k}}{2 \omega_{r}} \\
& \times \sum_{n=1}^{m} \cos \left[(h+k) \omega_{\mathrm{e}} t-(h+k)(n-1) \frac{2 \pi}{m}+\left(\theta_{e h}+\theta_{i k}\right)\right] .
\end{aligned}
$$

It should be noted from (12) and (13) that each harmonics pair of internal voltage and phase current produce an nonzero torque only when $h=k$. Otherwise, $T_{1}{ }^{h, k}$ and $T_{2}^{h, k}$ are both cosine functions of $\omega_{e} t$, hence their average value are always equal to zero. Therefore, harmonics of internal voltage produce torque ripples which are not desirable. However, for some harmonics the instantaneous value of produced electromagnetic torque is zero. The electromagnetic torque equations of $m$-phase machine based on different scenarios for harmonics pair of internal voltage and phase current are illustrated in Table 1.

\subsection{2-phase machine $(m=2)$}

For two phase machines the phase difference between phases is a coefficient of $\pi / \mathrm{m}$ instead of $2 \pi / \mathrm{m}$. Therefore:

$$
\begin{gathered}
e_{n}\left(\omega_{e} t\right)=\sum_{h=1}^{\infty} E_{h} \cos \left[h \omega_{e} t-h(n-1) \frac{\pi}{m}+\theta_{e h}\right] \\
n=1,2, \\
i_{n}\left(\omega_{e} t\right)=\sum_{k=1}^{\infty} I_{k} \cos \left[k \omega_{e} t-k(n-1) \frac{\pi}{m}+\theta_{i k}\right] \\
n=1,2 .
\end{gathered}
$$

Instantaneous electromagnetic torque $T_{e}^{h, k}$ is equal to summation of $T_{1}^{h, k}$ and $T_{2}^{h, k}$ which are:

$T_{1}^{h, k}\left(\omega_{e} t\right)=\frac{E_{h} I_{k}}{2 \omega_{r}}$

$\times \sum_{n=1}^{m} \cos \left[(h-k) \omega_{\mathrm{e}} t-(h-k)(n-1) \frac{\pi}{m}+\left(\theta_{e h}-\theta_{i k}\right)\right]$,

$T_{2}^{h, k}\left(\omega_{e} t\right)=\frac{E_{h} I_{k}}{2 \omega_{r}}$

$\times \sum_{n=1}^{m} \cos \left[(h+k) \omega_{\mathrm{e}} t-(h+k)(n-1) \frac{\pi}{m}+\left(\theta_{e h}+\theta_{i k}\right)\right]$.

The electromagnetic torque equations of 2-phase machine based on different scenarios for harmonics pair of internal voltage and phase current are illustrated in Table 1.

\subsection{Single phase machine $(m=1)$}

For single phase machines, instantaneous electromagnetic torque $T_{e}^{h, k}$ is:

$T_{e}^{h, k}\left(\omega_{e} t\right)=\frac{E_{h} I_{k}}{\omega_{r}} \cos \left(h \omega_{\mathrm{e}} t+\theta_{e h}\right) \cos \left(k \omega_{\mathrm{e}} t+\theta_{i k}\right)$,

which could be expressed by summation of $T_{1}^{h, k}$ and $T_{2}^{h, k}$ described as:

$$
\begin{aligned}
& T_{1}^{h, k}\left(\omega_{e} t\right)=\frac{E_{h} I_{k}}{2 \omega_{r}} \cos \left[(h-k) \omega_{e} t+\left(\theta_{e h}-\theta_{i k}\right)\right], \\
& T_{2}^{h, k}\left(\omega_{e} t\right)=\frac{E_{h} I_{k}}{2 \omega_{r}} \cos \left[(h+k) \omega_{e} t+\left(\theta_{e h}+\theta_{i k}\right)\right] .
\end{aligned}
$$

The electromagnetic torque equations of single phase machine based on different scenarios for harmonics pair of internal voltage and phase current are illustrated in Table 1.

\section{A discussion on torque ripples}

For the most of the synchronous machines, only odd harmonics exist in the waveforms of internal voltages and phase currents. Even harmonics in the internal voltage is a consequence of 1) Asymmetry of the machine and 2) Even harmonics in the field current of the rotor wounded machines. TFPM machines are often symmetrical and don't have the field current. Therefore, for these machines it is preferable to consider only odd harmonics of the internal voltage. On the hand, even harmonics in the phase currents can be produced as a result of even harmonics in the terminal or internal voltage or odd harmonics in the winding inductances, which are not the case in TFPM machines.

Table 2 summarizes the results of section 3, in which only odd harmonics of the internal voltage and phase current are considered. In this table, harmonic pairs of the internal voltage and phase current which take part in the electromagnetic 
Table 1: The electromagnetic torque equations based on different scenarios for harmonics pair of internal voltage and phase current

\begin{tabular}{|c|c|c|c|c|}
\hline & & & $T_{I}^{h, k}$ & $T_{2}^{h, k}$ \\
\hline \multirow{6}{*}{ 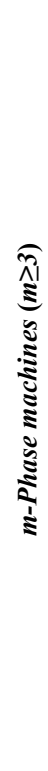 } & \multirow{2}{*}{$\frac{\pi}{\pi}$} & 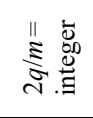 & $T_{1}^{q, q}\left(\omega_{e} t\right)=\frac{m E_{q} I_{q}}{2 \omega_{r}} \cos \left(\theta_{e q}-\theta_{i q}\right)$ & $T_{2}^{q, q}\left(\omega_{e} t\right)=\frac{E_{q} I_{q}}{2 \omega_{r}} \sum_{n=1}^{m} \cos \left[2 q \omega_{\mathrm{e}} t+\left(\theta_{e q}+\theta_{i q}\right)\right]$ \\
\hline & & 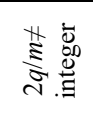 & $T_{1}^{q, q}\left(\omega_{e} t\right)=\frac{m E_{q} I_{q}}{2 \omega_{r}} \cos \left(\theta_{e q}-\theta_{i q}\right)$ & 0 \\
\hline & \multirow{4}{*}{$\underline{\underline{z}}$} & 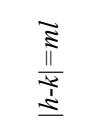 & $T_{1}^{h, k}\left(\omega_{e} t\right)=\frac{E_{h} I_{k}}{2 \omega_{r}} \sum_{n=1}^{m} \cos \left[m l \omega_{\mathrm{e}} t+\left(\theta_{e h}-\theta_{i k}\right)\right]$ & 0 \\
\hline & & $\underset{ \pm}{\stackrel{\Xi}{ \pm}}$ & 0 & $T_{2}^{h, k}\left(\omega_{e} t\right)=\frac{E_{h} I_{k}}{2 \omega_{r}} \sum_{n=1}^{m} \cos \left[m l \omega_{\mathrm{e}} t+\left(\theta_{e h}+\theta_{i k}\right)\right]$ \\
\hline & & 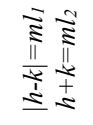 & $T_{1}^{h, k}\left(\omega_{e} t\right)=\frac{E_{h} I_{k}}{2 \omega_{r}} \sum_{n=1}^{m} \cos \left[m l \omega_{\mathrm{e}} t+\left(\theta_{e h}-\theta_{i k}\right)\right]$ & $T_{2}^{h, k}\left(\omega_{e} t\right)=\frac{E_{h} I_{k}}{2 \omega_{r}} \sum_{n=1}^{m} \cos \left[m l \omega_{\mathrm{e}} t+\left(\theta_{e h}+\theta_{i k}\right)\right]$ \\
\hline & & $\frac{\tilde{y}}{0}$ & 0 & 0 \\
\hline \multirow{6}{*}{ 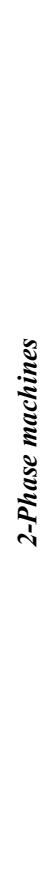 } & $\pi$ & 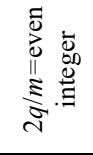 & $T_{1}^{q, q}\left(\omega_{e} t\right)=\frac{m E_{q} I_{q}}{2 \omega_{r}} \cos \left(\theta_{e q}-\theta_{i q}\right)$ & $T_{2}^{q, q}\left(\omega_{e} t\right)=\frac{E_{q} I_{q}}{2 \omega_{r}} \sum_{n=1}^{m} \cos \left[2 q \omega_{\mathrm{e}} t+\left(\theta_{e q}+\theta_{i q}\right)\right]$ \\
\hline & $=$ & 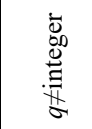 & $T_{1}^{q, q}\left(\omega_{e} t\right)=\frac{m E_{q} I_{q}}{2 \omega_{r}} \cos \left(\theta_{e q}-\theta_{i q}\right)$ & 0 \\
\hline & \multirow{4}{*}{ \pm} & 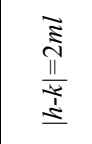 & $T_{1}^{h, k}\left(\omega_{e} t\right)=\frac{E_{h} I_{k}}{2 \omega_{r}} \sum_{n=1}^{m} \cos \left[2 m l \omega_{\mathrm{e}} t+\left(\theta_{e h}-\theta_{i k}\right)\right]$, & 0 \\
\hline & & 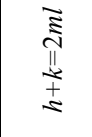 & 0 & $T_{2}^{h, k}\left(\omega_{e} t\right)=\frac{E_{h} I_{k}}{2 \omega_{r}} \sum_{n=1}^{m} \cos \left[2 m l \omega_{\mathrm{e}} t+\left(\theta_{e h}+\theta_{i k}\right)\right]$ \\
\hline & & 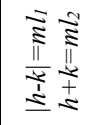 & $T_{1}^{h, k}\left(\omega_{e} t\right)=\frac{E_{h} I_{k}}{2 \omega_{r}} \sum_{n=1}^{m} \cos \left[2 m l \omega_{\mathrm{e}} t+\left(\theta_{e h}-\theta_{i k}\right)\right]$, & $T_{1}^{h, k}\left(\omega_{e} t\right)=\frac{E_{h} I_{k}}{2 \omega_{r}} \sum_{n=1}^{m} \cos \left[2 m l \omega_{\mathrm{e}} t+\left(\theta_{e h}-\theta_{i k}\right)\right]$ \\
\hline & & $\frac{D}{0}$ & 0 & 0 \\
\hline \multirow{2}{*}{ 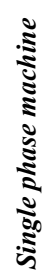 } & & $\frac{\pi}{\pi}$ & $T_{1}^{q, q}\left(\omega_{e} t\right)=\frac{E_{q} I_{q}}{2 \omega_{r}} \cos \left(\theta_{e q}-\theta_{i q}\right)$ & $T_{2}^{q, q}\left(\omega_{e} t\right)=\frac{E_{q} I_{q}}{2 \omega_{r}} \cos \left[2 q \omega_{e} t+\left(\theta_{e q}+\theta_{i q}\right)\right]$ \\
\hline & & 吾 & 0 & 0 \\
\hline
\end{tabular}

$l, l_{1}, l_{2}=1,2,3 \ldots$ 
Table 2: Harmonic pairs of internal voltage and phase current affecting the electromagnetic torque ripples of $\mathrm{m}$ phase machines

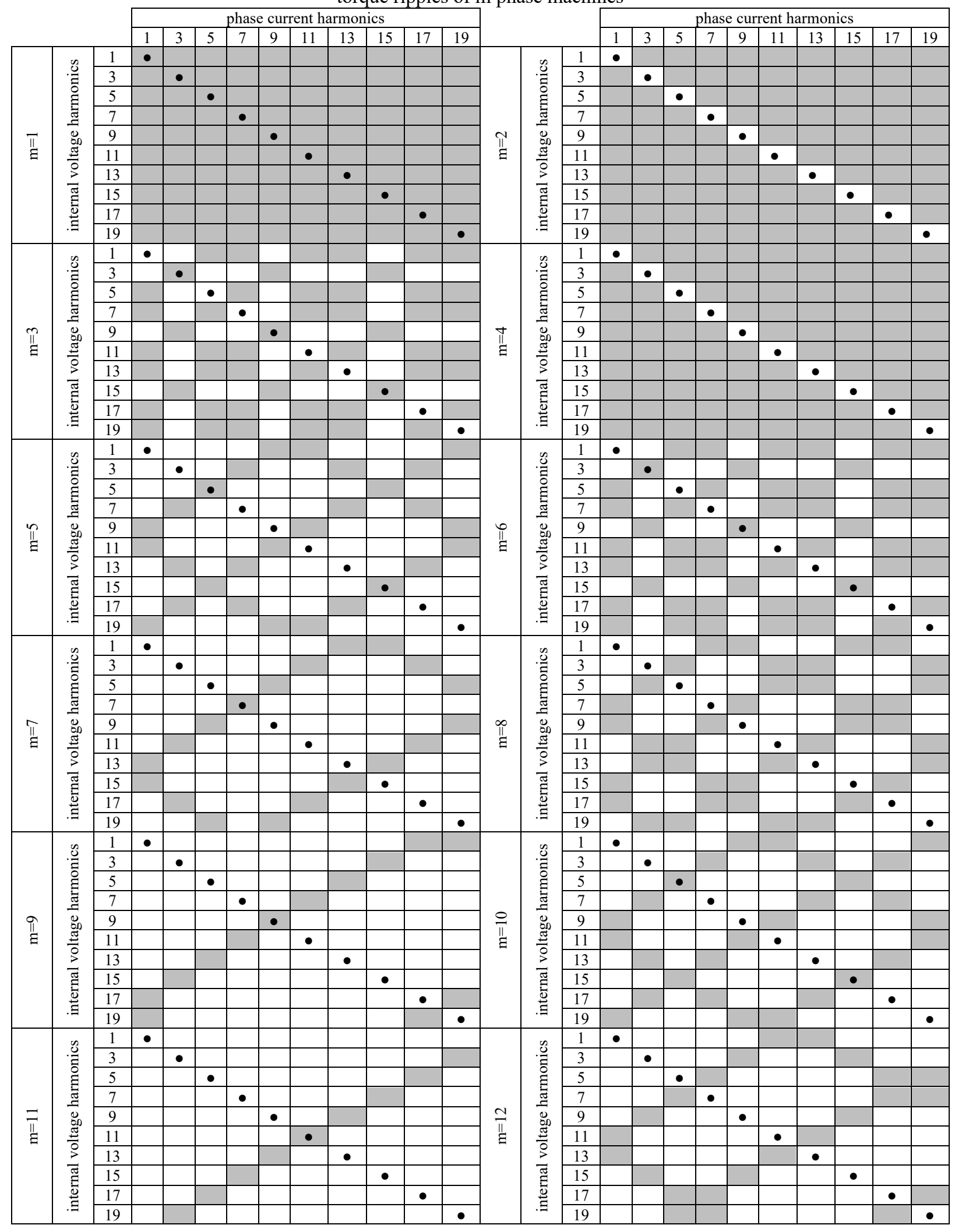


torque ripples for the m-phase synchronous machines are specified with gray color. Also, black circles show harmonic pairs which produce harmonic components of electromagnetic torque with nonzero average value.

Following results could be deduced from the analysis of Table 2:

1. Since, harmonics of the internal voltage and phase current are odd, their summation and subtraction are always even. Therefore, according to the results of section 3 harmonics of electromagnetic torque are always even.

2. For an even number of phases, except 2-phase machines, harmonic orders of electromagnetic torque are integer coefficients of $m$. For an odd number of phases, harmonic orders of electromagnetic torque are even integer coefficients of $m$. Orders of the torque harmonics of 2-phase machines are even integer coefficients of 2 .

3. Harmonic pairs which have the same order always produce a torque component with nonzero average value. However, some of these pairs take part in the torque ripples depending on the number of phases. For example, harmonics order 5 of the internal voltage and phase current take part in producing torque ripples in a 5-phase machine while in a 3phase motor this pair doesn't produce torque ripples.

4. Increasing the number of phases would not necessarily decrease number and amplitudes of harmonics of electromagnetic torque (for example, a 5-phase or a 7-phase machine has less number of harmonics than an 8-phase one), while for a machine with odd number of phases the number of harmonic components of electromagnetic torque is decreased as a consequence of increasing number of phases. However, without sufficient information about amplitudes and phase angles of the internal voltage and current harmonics it is impossible to talk accurately about percentage of the electromagnetic torque ripples.

5. Some multi-phase systems could be created by other multi-phase systems and its negative sign phase voltages (For example, 4-phase, 6-phase, and 10phase systems could be created by 2-phase, 3-phase, and 5-phase systems, respectively). For a machine with these multi-phase supplies, the harmonic orders of electromagnetic torque are similar to the harmonics of the creating system. For example, harmonic orders of 6-phase and 3-phase machines are the same, while harmonics of 8-phase and 4phase machines are different, because an 8-phase system cannot be created by a 4-phase system.

6. By knowing or guessing orders and amplitudes of the internal voltage and phase current harmonics, the optimal number of phases can be specified by a design-optimization procedure in a way that the harmonics of the internal voltage or phase current with highest amplitudes do not take part in producing of torque ripples.
7. Odd number of phases results in less number of harmonic components in the electromagnetic torque. For example, 3-phase, 7-phase, and 11-phase have less number of harmonics compared to 4-phase, 8phase, and 12-phase, respectively.

\section{Determination of optimal number of phases}

\subsection{Case study}

Based on detailed design algorithm presented in section 2, a $500 \mathrm{~kW}, 300 \mathrm{rpm}$ Claw Pole TFPM motor has been designed for marine propulsion systems. Internal voltage current waveforms of the case study motor could be obtained by finite element analysis which only one pole pair of each machine is simulated. The basic dimensions of the case study are depicted in Fig. 4. For FE modelling, the dimensions mentioned in Fig. 4, the ratings and parameters of the case study motor are listed in Table 3. Also the materials used in the machine structure are given in Table 4. By As seen in Table 3, the case study motor is a high power TFPM machine which operates with a relatively very low rated voltage. As mentioned previously, for a low voltage machines, THD of the current is usually much lower than the THD of the internal voltage but amplitudes of the current harmonics are sufficiently large having a considerable effect on the electromagnetic torque ripples.

Table 3: Ratings and parameters of the case study motor

\begin{tabular}{|c|c|c|}
\hline Symbol & Quantity & Value \\
\hline$P$ & rated power & $500 \mathrm{~kW}$ \\
\hline$n_{s}$ & rated speed & $300 \mathrm{rpm}$ \\
\hline$f$ & rated frequency & $300 \mathrm{~Hz}$ \\
\hline$p$ & number of pole pairs & 60 \\
\hline$V_{m}$ & $\begin{array}{l}\text { maximum available phase } \\
\text { voltage amplitude }\end{array}$ & $105 \mathrm{~V}$ \\
\hline$R$ & $\begin{array}{l}\text { armature winding resistance of } \\
\text { each phase }\end{array}$ & $\begin{array}{c}3.4 \times 10^{-4} \\
\Omega\end{array}$ \\
\hline$m$ & number of phases & 6 \\
\hline$B_{g}$ & average flux density in air gap & $0.3529 \mathrm{~T}$ \\
\hline$B_{m}$ & $\begin{array}{l}\text { flux density of PM at operating } \\
\text { point }\end{array}$ & $0.8994 \mathrm{~T}$ \\
\hline$g$ & air gap length & $1 \mathrm{~mm}$ \\
\hline$D_{o}$ & outer diameter & $1292 \mathrm{~mm}$ \\
\hline$D_{i r}$ & inner diameter & $1182 \mathrm{~mm}$ \\
\hline$D_{g}$ & air gap surface diameter & $1200 \mathrm{~mm}$ \\
\hline$d_{w s}$ & redial length of stator slot & $12.5 \mathrm{~mm}$ \\
\hline$d_{c s}$ & thickness of stator core back & $12 \mathrm{~mm}$ \\
\hline$d_{o s}$ & length of stator tooth & $21.5 \mathrm{~mm}$ \\
\hline$H_{p m}$ & redial length of PMs & $8 \mathrm{~mm}$ \\
\hline$L_{s}$ & axial length of each phase & $100 \mathrm{~mm}$ \\
\hline$L_{s s}$ & slot axial length & $43 \mathrm{~mm}$ \\
\hline$K_{s}$ & ratio of the slot axial length & 0.43 \\
\hline$K_{c o}$ & $\begin{array}{l}\text { ratio of the stator pole area to } \\
\text { rotor pole area }\end{array}$ & 0.5 \\
\hline$K_{m}$ & $\begin{array}{l}\text { ratio of magnet arc to flux } \\
\text { concentrator arc }\end{array}$ & 0.7 \\
\hline$K_{l p m}$ & PM leakage coefficient & 0.24 \\
\hline$K_{l t}$ & stator tooth leakage coefficient & 0.0066 \\
\hline
\end{tabular}


Table 4: Materials employed in the structure of case study motor

\begin{tabular}{lc}
\hline Part of machine & Material \\
\hline stator core & Somaloy500+0.5\%Kenolube_800MPa \\
rotor flux & Somaloy500+0.5\%Kenolube_800MPa \\
concentrators & \\
permanent & NEOMAX-32EH \\
magnets & \\
armature & Copper \\
winding & \\
\hline
\end{tabular}

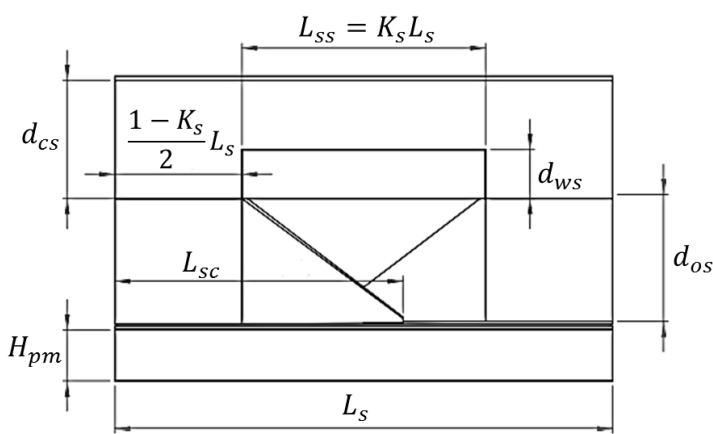

(a)

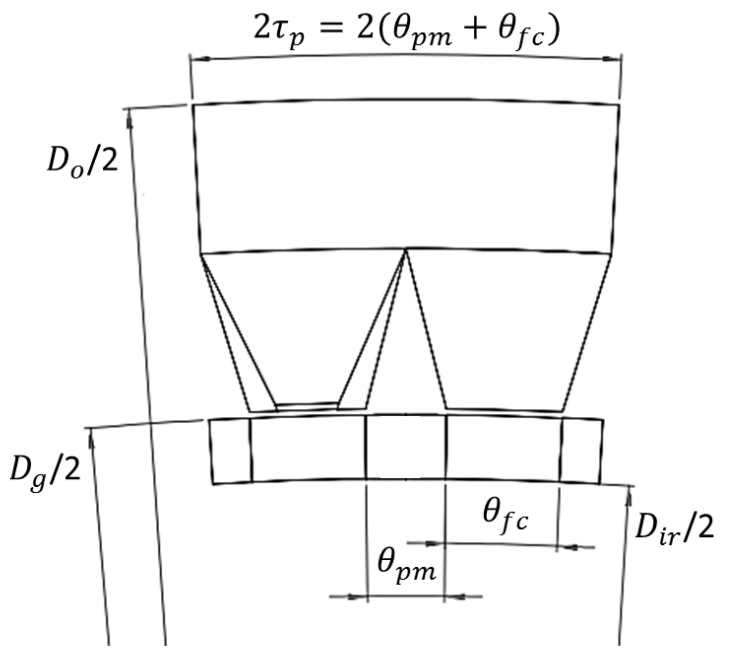

(b)

Figure 4: Main sizing parameters of the claw pole TFPM motor (a) Side view (b) Front view.

It should be noted that due to electromagnetic independency of phases in a Claw Pole TFPM machine, the design process of the machine is essentially based on per phase calculations. By the other words, for designing a $P \mathrm{~kW}$ $m$-phase motor, it would be required to design $m$ identical single-phase machine with the rated of each equal to $P / m \mathrm{~kW}$. Since the case study motor is employed where only 3-phase source is available, it should have been designed with 3 phases. However, because of the outer diameter limit, 6 phases should be connected together in order to provide the required output power of $1 \mathrm{MW}$. As mentioned earlier, it is possible to build a 6-phase system using a 3-phase system.

\subsection{Analysis of the case study motor}

Internal voltage waveform of the case study motor is obtained by use of finite element analysis. Internal voltage of each phase is calculated as time derivative of flux linkage of the relevant phase winding at open circuited condition. $t=0$ is chosen as a time when the flux linkage of phase ' $a$ ' is minimum and hence, the relevant internal voltage is zero. Internal voltage waveform of phase ' $a$ ' is depicted in Fig. 5. As seen from this figure, the waveform of internal voltage is too far to be assumed pure sinusoidal. Although this distorted waveform will illustrate most clearly all purposes and goals of the present paper, but as explained in [27], it is possible to establish almost a sinusoidal internal voltage through some geometrical modifications if required. The results of Discrete Furrier Transform (DFT) applied to the internal voltage are given in Table 5. Hereafter, the Furrier series of the periodic function $F(x)$ will be presented as follows:

$$
F(x)=\sum_{h=1}^{\infty} C_{h} \cos \left(h x+\varphi_{h}\right),
$$

where $C_{h}$ and $\varphi_{h}$ are the amplitude and phase angle of $h^{\text {th }}$ harmonic component of $F$. Table 5 shows that the internal voltage involves odd harmonics only. Variation of selfinductance of phase ' $a$ ' with respect to rotor position is illustrated in Fig. 6. Table 6 presents the results of DFT applied to self-inductance, which contains the even harmonics only. As mentioned already the mutual inductance between each pair of the phases is zero, so the resistances and

Table 5: Harmonics of the Internal Voltage of case study machine

\begin{tabular}{ccc}
\hline Order & Amplitude $(\mathrm{V})$ & Phase $(\mathrm{deg})$ \\
\hline 1 & 80.54 & -90 \\
3 & 29.70 & 90 \\
5 & 14.58 & -90 \\
7 & 2.70 & 90 \\
9 & 0.71 & 90 \\
11 & 2.93 & -90 \\
13 & 2.44 & 90 \\
15 & 2.13 & -90 \\
17 & 1.24 & 90 \\
19 & 1.06 & -90 \\
21 & 0.27 & 90 \\
23 & 0.10 & -90 \\
25 & 0 & 0 \\
\hline
\end{tabular}

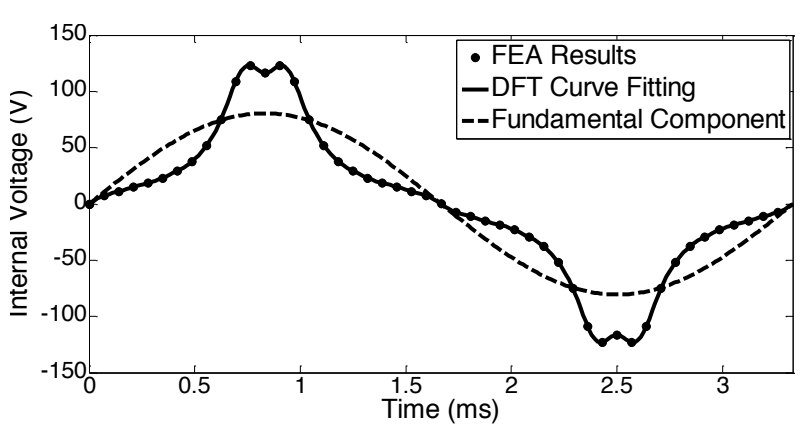

Figure 5: Internal voltage waveform and its fundamental component for phase 'a'. 
Table 6: Harmonics of Self Inductance of phase 'a' of case study motor

\begin{tabular}{ccc}
\hline Order & Amplitude $(\mathrm{H})$ & Phase $(\mathrm{deg})$ \\
\hline 0 & $2.08 \mathrm{E}-05$ & 0 \\
2 & $6.61 \mathrm{E}-07$ & 180 \\
4 & $2.70 \mathrm{E}-07$ & 0 \\
6 & $1.04 \mathrm{E}-07$ & -180 \\
8 & $6.16 \mathrm{E}-08$ & 0 \\
10 & $1.95 \mathrm{E}-08$ & -180 \\
12 & $1.18 \mathrm{E}-08$ & 0 \\
14 & $1.77 \mathrm{E}-09$ & 0 \\
16 & $2.63 \mathrm{E}-09$ & 180 \\
18 & $3.69 \mathrm{E}-09$ & 0 \\
20 & $2.10 \mathrm{E}-09$ & -180 \\
22 & $3.97 \mathrm{E}-09$ & 180 \\
24 & $1.44 \mathrm{E}-09$ & 180 \\
\hline
\end{tabular}

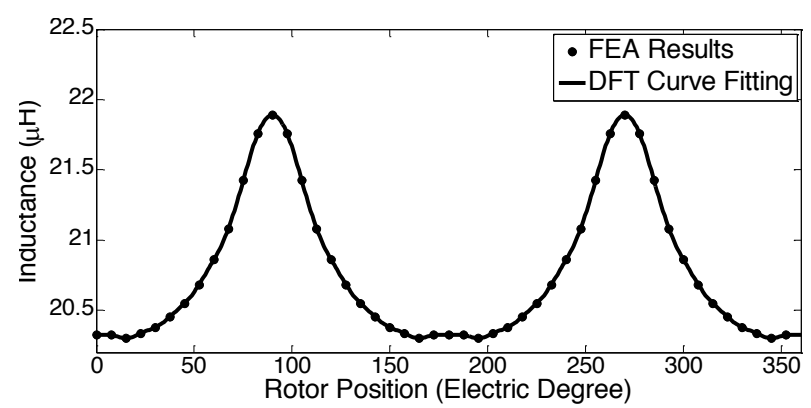

Figure 6: Self-inductance of phase 'a' versus rotor position.

self-inductances of the windings and the back emfs are the only parameters required for modeling and analyzing a multiphase TFPM machine performance.

Having internal voltages, self-inductances and resistances of all phases, phase currents of the motor is obtained at each load through a simulation of dynamic transient model of the machine. The current of phase 'a' at steady-state is as shown in Fig. 7 when the motor is running its rated load. DFT results of phase ' $a$ ' current are given in Table 7 . Since the internal voltage involves odd harmonics and the inductance contains even order harmonics only, all harmonic components of the phase current are of odd orders. In order to compare the torque ripples of single-phase and 6-phase motors, the instantaneous torques of both machines normalized with respect to their average value are shown in Fig. 8. It is clearly visible from this figure, that the torque ripples of 6-phase machine are much lower than the single phase motor as expected. Table 8

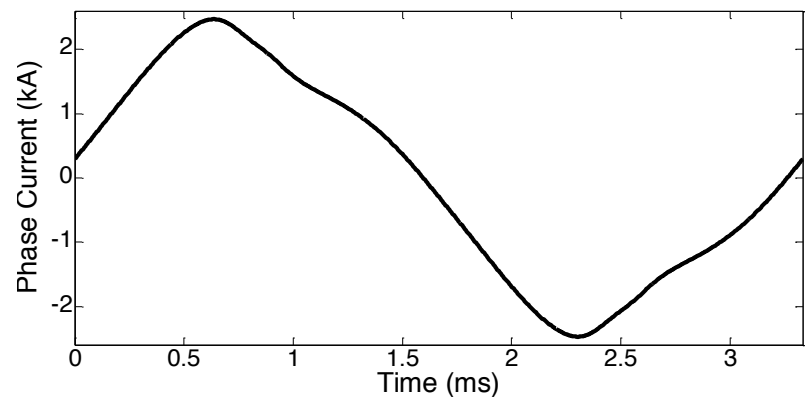

Figure 7: Current waveform of phase 'a'.
Table 7: Harmonics of phase 'a' Current for case study motor

\begin{tabular}{ccc}
\hline Order & Amplitude $(\mathrm{A})$ & Phase $(\mathrm{deg})$ \\
\hline 1 & 2192.72 & -77.38 \\
3 & 251.78 & -171.17 \\
5 & 70.97 & 11.32 \\
7 & 10.27 & -135.80 \\
9 & 5.17 & 127.30 \\
11 & 7.50 & -18.37 \\
13 & 5.04 & 166.11 \\
15 & 3.60 & -6.38 \\
17 & 1.77 & 178.61 \\
19 & 1.31 & -0.64 \\
21 & 0.22 & 134.48 \\
23 & 0.20 & -59.59 \\
25 & 0.08 & -96.67 \\
\hline
\end{tabular}

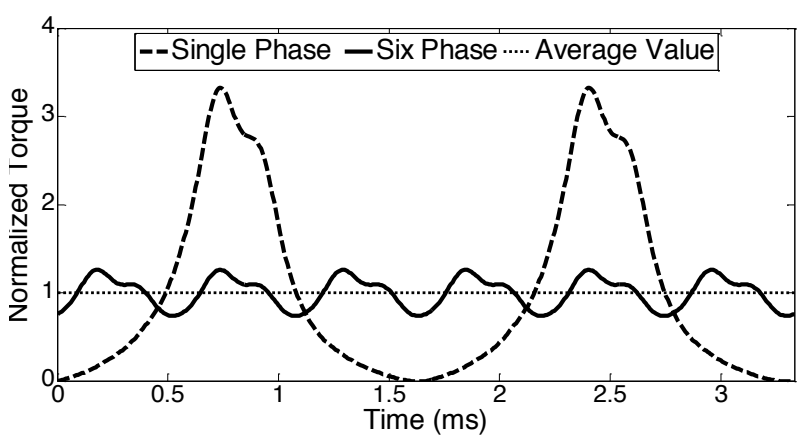

Figure 8: Normalized electromagnetic torques for singlephase and 6-phase motors.

Table 8: Harmonics of Electromagnetic Torques for both single-phase and 6-phase motors

\begin{tabular}{ccccc}
\hline & $\begin{array}{c}\text { Torque components of } \\
\text { Single-phase motor }\end{array}$ & $\begin{array}{c}\text { Torque components of } \\
\text { 6-phase motor }\end{array}$ \\
\hline Order & $\begin{array}{c}\text { Amplitude } \\
(\text { N.m) }\end{array}$ & $\begin{array}{c}\text { Phase } \\
(\mathrm{deg})\end{array}$ & $\begin{array}{c}\text { Amplitude } \\
(\mathrm{N} . \mathrm{m})\end{array}$ & $\begin{array}{c}\text { Phase } \\
(\mathrm{deg})\end{array}$ \\
\hline 0 & 2721.19 & 0.00 & 16327.14 & 0 \\
2 & 3749.38 & -169.54 & 0 & 0 \\
4 & 1525.18 & 19.78 & 0 & 0 \\
6 & 624.36 & -150.26 & 3755.16 & -150.26 \\
8 & 137.46 & 73.51 & 0 & 0 \\
10 & 145.36 & -17.19 & 0 & 0 \\
12 & 189.91 & -176.70 & 1142.17 & -176.70 \\
14 & 159.00 & 8.83 & 0 & 0 \\
16 & 116.85 & -166.70 & 0 & 0 \\
18 & 78.97 & 13.76 & 474.98 & 13.76 \\
20 & 47.18 & -159.21 & 0 & 0 \\
22 & 14.28 & 34.74 & 0 & 0 \\
24 & 4.25 & -133.13 & 25.56 & -133.13 \\
26 & 0.46 & 140.97 & 0 & 0 \\
28 & 0.46 & 66.62 & 0 & 0 \\
30 & 0.48 & -102.51 & 2.88 & -102.51 \\
32 & 0.31 & 79.60 & 0 & 0 \\
34 & 0.19 & -99.68 & 0 & 0 \\
36 & 0.09 & 79.30 & 0.54 & 79.30 \\
38 & 0.04 & -103.35 & 0 & 0 \\
\hline & & & &
\end{tabular}


presents DFT results of the electromagnetic torques for both single phase and 6-phase motors. As seen from this table the harmonic orders of the electromagnetic torques are even, because the harmonic orders of both internal voltage and current are odd. Also, according Table 7 and explanation given in section 4 , the harmonic orders of torques for the single phase and 6-phase machines are coefficients of 2 and 6 , respectively.

\subsection{Optimal number of phases}

One of the most important advantages of Claw Pole TFPM machines is that a multi-phase structure is simply constructed by stacking a few single-phase motors along the axis of machine. It was found that the torque ripple of each phase of the study motor is more than $300 \%$ of its average torque (Fig. 8 ). However, by bringing six of these single-phase motors together in a six-phase motor, the total torque ripple reduces to about $50 \%$ of the total average torque. Regardless of the average value of total output power or torque, it is interesting to find out the number of phases optimally applying the same number of the previously manufactured single-phase motors which presents the least electromagnetic torque ripples for the final assembled multi-phase motor. Fig. 9 shows variations of the everlasting electromagnetic torques of a few multi-phase motors each assembled applying appropriate number of the single-phase study motors. For each motor the steady-state instantaneous torque is evaluated using steady-state values of the internal voltages and phase currents in equation (8). It is evident and as seen clearly from this figure too; the average torque increases by increasing the number of phases. The torque ripples in percentage of the average values are shown in Fig. 10 for a different numbers of the phases for comparison.

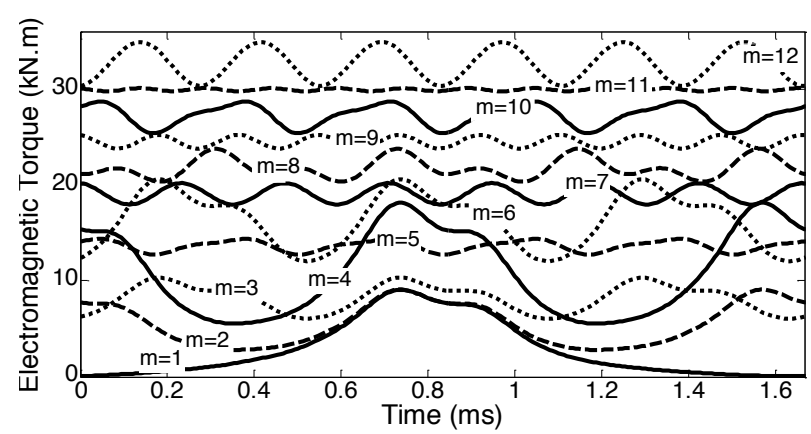

Figure 9: Electromagnetic torques of a few Claw Pole TFPM motors with different phase number.

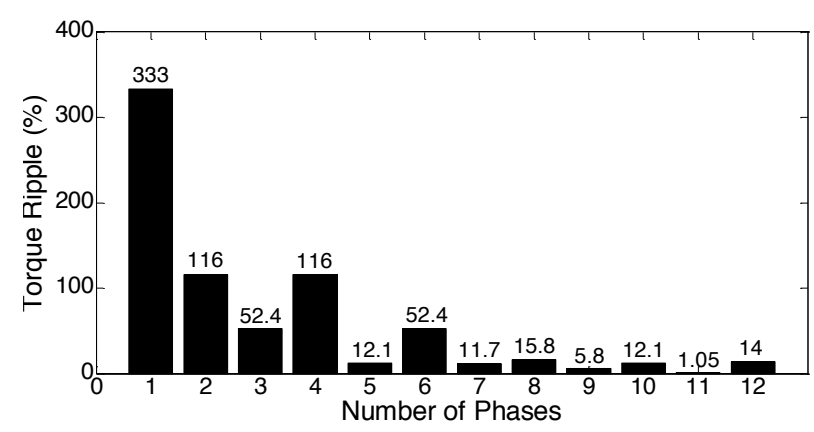

Figure 10: Percentages of electromagnetic torque ripples for a few Claw Pole TFPM motors with different phase number.
According to this figure the optimum number of phases will be 11 regarding the presentation of minimum torque ripples. However, this is true only when all the motors are built employing a few of the case study single-phase motors with the associated back emf and phase current illustrated in Fig. 5 and Fig. 7 respectively. However, it is interesting as mentioned already in section 4 and can be seen from Fig. 10, torque ripples for 4-phase and 2-phase motors are exactly the same and the torque ripples of 3-phase and 6-phase machines are equal and so on.

From Fig. 10 it could be found that the normalized torque ripples for 5-phase and 7-phase are almost equal. By ignoring higher order harmonics of the phase current but taking all harmonics of the internal voltage into account, Table 2 and Table 5 show that for 5-phase machine $9^{\text {th }}, 10^{\text {th }}, 19^{\text {th }}$, and $21^{\text {th }}$ harmonics of the internal voltage take part in producing torque ripples. However, for the 7-phase machine only $13^{\text {th }}$ and $15^{\text {th }}$ harmonics of the internal voltage among the harmonics up to $25^{\text {th }}$ produce torque ripples with comparatively big amplitude due to great values of $13^{\text {th }}$ and $15^{\text {th }}$ harmonics' amplitudes while lower order harmonics do not involve in the torque ripples. In Fig. 10, the extracted results based on electromagnetic torque equations for different scenarios listed in Table 1 and also harmonic pairs of the internal voltage and phase current taking part in the electromagnetic torque ripples depicted in Table 2, indicate that increasing the number of phases would not necessarily decrease the per-unit values of the torque ripple. For example, increasing the number of phases from 5 to 6 leads to a rise in torque ripple from $12.1 \%$ to $52.4 \%$.

\section{Conclusion}

In this paper, the structure of the Claw Pole Transverse Flux Permanent Magnet machines was introduced with some details and then a few sizing equations of the machine were presented. The existing correlations between the swimming around the average value or ripples of the electromagnetic torque and the number of phases, harmonics of the internal voltages and harmonics of the phase currents are discussed mathematically. It is shown by both the deuced equations and simulation results that existing odd harmonics in the internal voltages and phase currents produce torque ripples with even harmonics content only. Also it was shown that for an $\mathrm{m}$ phase machine $(m \neq 2)$ when $m$ is an even integer those harmonic pairs of the internal voltage and phase currents take part in torque ripples that summation or subtraction of their orders are an integer coefficient of $\mathrm{m}$. inversely for an odd integer $\mathrm{m}$ only those harmonic pairs of the internal voltage and phase currents produce torque ripples where the summation or subtraction of their orders are even integer coefficient of $\mathrm{m}$. For a 2-phase machine only those harmonic pairs of the internal voltage and phase current which summation or subtraction of their orders are even integer coefficient of 2 present in the torque ripples. Finally, it was concluded that any increase in the phase numbers does not necessarily yield to a lower torque ripples. An appropriate number of phases for a multi-phase motor with a least torque ripples can be specified by considering amplitudes of all harmonics of the internal voltage and phase current of the 
single-phase machine which is decided to be employed in the multi-phase motor. However, as a law of thumb, it could be said that odd number of phases yields to a somewhat smooth torque comparing with the motor with almost the same range but even number of phases.

\section{References}

[1] H. Weh, H. Hoffmann, J. Landrath, New permanent excited magnet synchronous machine with high efficiency at low speeds, ICEMS, pp. 35-40, 1990.

[2] D. Li, R. Qu, T. A. Lipo, High-power-factor Vernier permanent-magnet machines, IEEE T. Ind. Appl., 50(6): 3664-3674, 2014.

[3] D. Xianminga, L. Naa, S. Yuandaa, L. Shaowub, Y. Zongbina, Design and performance analysis of a novel transverse flux permanent-magnet motor, Int. J. Appl. Electrom., 56(4): 623$635,2018$.

[4] J. F. Gieras, Permanent magnet motor technology: design and applications: High power density brushless motors, CRC Press, Taylor \& Francis Group, New York, 2010.

[5] X. Zhao, S. Niu, Design of a Novel consequent-pole transverse-flux machine with improved permanent magnet utilization, IEEE T. Magn., 53(11): 1-5, 2017.

[6] C. Liu, G. Lei, B. Ma, Y. Wang, Y. Guo, J. Zhu, Development of a new low-cost 3-d flux transverse flux FSPMM with soft magnetic composite cores and ferrite magnets, IEEE Trans. Magn., 53(11): 1-5, 2017.

[7] S. Ahmadi, M. Mirsalim, A novel quad-leg transverse-flux permanent magnet linear motor for 3-D printer applications, 2019 10th International Power Electronics, Drive Systems and Technologies Conference (PEDSTC), Shiraz, Iran, 2019.

[8] Y. Hsu, M. Tsai, Development of a novel transverse flux wheel motor, IEEE T. Magn., 47(10): 3677-3680, 2011.

[9] P. Zheng, Q. Zhao, J. Bai, B. Yu, Z. Song, J. Shang, Analysis and design of a transverse-flux dual rotor machine for powersplit hybrid electric vehicle applications, Energies, 6(12): 6548-6568, 2013.

[10] D. H. Kang, H. Weh, Design of an integrated propulsion, guidance, and levitation system by magnetically excited transverse flux linear motor (TFM-LM), IEEE Trans. Energy Conver., 19(3): 477-484, 2004.

[11] Z. Jia, L. Wu, W. Chen, L. Yu, Y. Cao, H. Jia, Optimization of transverse flux permanent magnet machine with double omega-hoop stator, 2019 IEEE International Electric Machines \& Drives Conference (IEMDC), San Diego, CA, USA, 2019.

[12] J. Soleimani, A. Ejlali, M. Moradkhani, Transverse flux permanent magnet generator design and optimization using response surface methodology applied in direct drive variable speed wind turbine system, PEN, 7(1): 36-53, 2019.

[13] G. Peng, J. Wei, Y. Shi, Z. Shao, L. Jian, A novel transverse flux permanent magnet disk wind power generator with $\mathrm{H}$ shaped stator cores, Energies, 11(4): 810, 2018.

[14] J. Oh, B. Kwon, Improved Transverse flux type permanent magnet reluctance generator with auxiliary rotor pole inserted permanent magnet, IEEE T. Magn., 50(11): 1-4, 2014.

[15] O. Dobzhanskyi, Comparison analysis of cylindrical and rectangular linear permanent magnet transverse-flux machines for wave energy applications, 2019 12th International Symposium on Linear Drives for Industry Applications (LDIA), Neuchatel, Switzerland, 2019.

[16] Y. Yamamoto, T. Koseki, Y. Aoyama, Proposal of C-core type transverse flux motor for ship propulsion -Increasing torque density by dense stator configuration-, AEM 2(3): 28-34, 2013
17] A. Alaeddini, A. Darabi, H. Tahanian, Influence of various structural factors of claw pole transverse flux permanent magnet machines on internal voltage using finite element analysis, Serb. J. Electr. Eng., 12(2): 129-143, 2015.

[18] M. A. Patel, S. C. Vora, Analysis of a fall-back transverse-flux permanent-magnet generator, IEEE T. Magn., 53(11): 1-5, 2017.

[19] K. Lu, P. O. Rasmussen, E. Ritchie, Design considerations of permanent magnet transverse flux machines, IEEE T. Magn., 47(10): 2804-2807, 2011.

[20] K. Lu, W. Wu, High torque density transverse flux machine without the need to use SMC material for 3-D flux paths, IEEE T. Magn., 51(3): 1-4, 2015.

[21] B. Zhang, A. Wang, M. Doppelbauer, Multi-objective optimization of a transverse flux machine with claw-pole and flux-concentrating structure, IEEE T. Magn., 52(8): 1-10, 2016.

[22] C. Liu, J. Zhu, Y. Wang, G. Lei, Y. Guo, X. Liu, Comparison of claw pole machines with different rotor structure, IEEE International Magnetics Conference (INTERMAG), Beijing, 2015.

[23] T. Husain, I. Hasan, Y. Sozer, I. Husain, E. Muljadi, A comprehensive review of permanent magnet transverse flux machines for direct drive applications, 2017 IEEE Energy Conversion Congress and Exposition (ECCE), Cincinnati, OH, USA, 2017.

[24] R. Islam, I. Husain, Analytical model for predicting noise and vibration in permanent-magnet synchronous motors, IEEE $T$. Ind. Appl., 46(6): 2346-2354, 2010.

[25] Yu Zeng, Ming Cheng, Guohai Liu, Wenxiang Zhao, Effects of magnet shape on torque capability of surface-mounted permanent magnet machine for servo applications, IEEE $T$. Ind. Electron., doi: 10.1109/TIE.2019.2910025, 2019.

[26] W. Zhao, T. A. Lipo, B. I. Kwon, Material-efficient permanent-magnet shape for torque pulsation minimization in SPM motors for automotive applications, IEEE Trans. Ind. Electr., 61(10): 5779-5787, 2014.

[27] A. Darabi, H. Tahanian, A. Alaeddini, R. Mirzahosseini, Steps towards a sinusoidal back EMF for a claw pole transverse flux permanent magnet synchronous machine, 4th Annual International Power Electronics, Drive Systems and Technologies Conference, Tehran, pp. 328-332, 2013.

[28] Y. Jung, M. Lim, M. Yoon, J. Jeong, J. Hong, Torque ripple reduction of IPMSM applying asymmetric rotor shape under certain load condition, IEEE T. Energy Conver., 33(1): 333-340, 2018.

[29] S. A. Evans, Salient pole shoe shapes of interior permanent magnet synchronous machines, The XIX International Conference on Electrical Machines - ICEM, Rome, Italy, 2010.

[30] Z. S. Du, T. A. Lipo, Efficient utilization of rare earth permanent-magnet materials and torque ripple reduction in interior permanent-magnet machines, IEEE T. Ind. Appl., 53(4): 3485-3495, 2017.

[31] H. Hong, J. Yoo, Shape design of the surface mounted permanent magnet in a synchronous machine, IEEE T. Magn., 47(8): 2109-2117, 2011.

[32] D. Wu, Z. Q. Zhu, W. Chu, Reduction of on-load terminal voltage distortion in fractional slot interior permanent magnet machines, IEEE T. Energy Conver., 31(3): 1161-1169, 2016.

[33] G. Liu, X. Du, W. Zhao, Q. Chen, Reduction of torque ripple in inset permanent magnet synchronous motor by magnets shifting, IEEE T. Magn., 53(2): 1-13, 2017.

[34] R. Deodhar, A. Pride, Non-uniformly spaced claw-pole stator, U.K. Patent Appl. GB2491880A, 2012. 
[35] R. P. Deodhar, A. Pride, J. J. Bremner, Design method and experimental verification of a novel technique for torque ripple reduction in stator claw-pole PM machines, IEEE $T$. Ind. Appl., 51(5): 3743-3750, 2015.

[36] X. Pei, Z. Sheng, Y. Zhou, Research on the mechanical characteristic of a novel building-block transverse flux permanent-magnetic motor (B-TFPM), 2016 IEEE International Conference on Aircraft Utility Systems (AUS), Beijing, 2016.

[37] W. Li, K. T. Chau, T. W. Ching, A six-phase transverse-fluxreversal linear machine for low-speed reciprocating power generation, 2015 IEEE International Electric Machines \& Drives Conference (IEMDC), Coeur d'Alene, ID, 2015.

[38] H. Wang, Y. Shi, B. Tang, X. Yuan, An investigation of fourphase flat-type TFPM and control system, 2009 Fourth International Conference on Innovative Computing, Information and Control (ICICIC), Kaohsiung, 2009.

[39] H. Wang, Y. Shi, J. Lu, X. Yuan, Design and application of new topology of transverse flux permanent-magnet motor with driving system, 2010 Third International Symposium on Intelligent Information Technology and Security Informatics, Jinggangshan, 2010.

[40] H. Ahn, G. Jang, J. Chang, S. Chung, D. Kang, Reduction of the torque ripple and magnetic force of a rotatory two-phase transverse flux machine using herringbone teeth, IEEE $T$. Magn., 44(11): 4066-4069, 2008.

[41] J. Wang, K. T. Chau, J. Z. Jiang, C. Yu, Design and analysis of a transverse flux permanent-magnet machine using threedimensional scalar magnetic potential finite element method, J. Appl. Phys., 103(7): 07F107-07F107-3, 2008.

[42] G. Q. Bao, J. K. Wang, D. Zhang, J. Z. Jiang, An investigation of multi-phase transverse flux permanent magnet machine, 2006 CES/IEEE 5th International Power Electronics and Motion Control Conference, Shanghai, 2006.

[43] P. Dickinson, A. G. Jack, B. C. Mecrow, Improved permanent magnet machines with claw pole armatures, 15 th International Conference on Electrical Machines (ICEM), 2002. 